\title{
Antibacterial and antibiofilm activity of selected polyphenolic compounds: An in vitro study on Staphylococcus aureus
}

\author{
Marina Kostić ${ }^{1}$, Marija Ivanov ${ }^{1}$, Dejan Stojković ${ }^{1}$, Ana Ćirić ${ }^{1}$, And Marina SoKović ${ }^{*}$ \\ ${ }^{1}$ Department of Plant Physiology, Institute for Biological Research "Siniša Stanković" - National Institute of Republic of Serbia, University of Belgrade, \\ Bulevar despota Stefana 142, 11000 Belgrade, Serbia. \\ *Corresponding author: mris@ibiss.bg.ac.rs
}

Received: November 5, 2020

Accepted: December 15 19, 2020

Published on-line: December 23, 2020

Published: December 25, 2020

\begin{abstract}
Staphylococcus aureus is a human pathogen that causes serious infections with high mortality rates. The antimicrobial activities of eight phenolic compounds (caffeic acid, chlorogenic acid, ferulic acid, morin, quercetin, isoquercitrin, rutin and hesperidin) were evaluated against planktonic and biofilm forming Staphylococcus aureus cells. Their ability to prevent biofilm formation via interference with bacterial cell adhesion and to reduce biomass of $24 \mathrm{~h}$ old biofilms has been addressed in this study. The antibacterial activities (MIC/MBC) were demonstrated using the microdilution method and the investigated compounds showed good activity against $S$. aureus isolates, with MICs in the range 0.05$0.4 \mathrm{mg} / \mathrm{mL}$. Also, they exhibited promising antibiofilm potential in dose depended manner. Among all tested compounds, morin and quercetin showed the best antibiofilm activity at MIC values. The observed antimicrobial potential of the studied natural products can serve as a starting point towards development of novel plant-based therapeutics for the treatment of common infections such as the ones caused by S. aureus.
\end{abstract}

Key words: antibacterial activity; phenolic compounds; Staphylococcus aureus; biofilm

\section{INTRODUCTION}

Staphylococcus aureus is an opportunistic pathogen frequently linked to skin and soft-tissue infections, osteomyelitis, septic arthritis, chronic sinusitis and tonsillitis (Chalmers and Wylam, 2020; Kostić et al., 2020a). In the case of bloodstream infection caused by this bacterium there is a serious concern due to high mortality rates: in the United States among 120000 S. aureus bloodstream infections recorded in 2017, 20000 were with death outcome (Kourtis et al., 2019). Chronic and persistent infections by this microorganism are correlated with its ability to establish biofilms (Figueiredo et al., 2017) - trait that is directly linked to antimicrobial resistance (Manandhar et al., 2018). Resistance of biofilms is caused by lower ability of drugs to penetrate through biofilm matrix and different physiology of biofilm cell compared to the cells growing in planktonic phase (Craft et al., 2019). Biofilms can be established on indwelling medical devices; including implanted artificial heart valves, catheters and joint prosthetics and these usually lead to increased duration of patients hospital stay. The process of biofilm formation starts by attachment of cells on the surface, while next phases include accumulation/maturation and subsequent detachment and dispersal of mature biofilms (Moormeier and Bayles, 2017). The main constituents of biofilm matrix include oligosaccharides, DNA, proteins and teichoic acids while a cyclic peptide, autoinducing peptide, serves as a messenger in the intercellular bacterial communication during biofilm establishment (Craft et al., 2019). Recent studies have highlighted the potential of different agents against $S$. aureus biofilms including mushrooms (Kostić et al., 2020b), fruit peel (Stojković et al., 2018), acidic amino acids (Warraich et al., 2020) and essential oils (Kerekes et al., 2019), but the search for efficient antibiofilm therapeutics is still running.

Compounds of natural origin have been seen as an attractive source of novel anti-quorum sensing agents including the ones with antibiofilm activities (Ćirić et al., 2020). Phenolic compounds are all over distributed phytochemicals found in majority of plant organs and tissues, including vegetables and fruits. They are specialized metabolites which biosynthesis goes through the phenylpropanoid and shikimic acid pathways. These compounds possess numerous bioactivities and, although they are not nutrients, dietary intake provides health-protective effects. Besides antioxidant activity, as one of the most studied bioactivities of phenolic compounds, an- 
timicrobial potential has also been explored (Smiljkovic et al., 2017; Stojković et al., 2013). However, their antibiofilm potential is in much lower proportion revealed compared to their antimicrobial effect towards planktonic cells (Smiljković et al., 2019).

Some recent studies (Ivanov et al., 2020; Slobodníková et al., 2016) highlighted a significant antibiofilm potential existing among the molecules from this group - a feature deserving more detailed experiments. This study aimed to further enlighten potential antimicrobial and antibiofilm role of selected phenolic compounds such as caffeic acid, chlorogenic acid, ferulic acid, morin, quercetin, isoquercitrin, rutin and hesperidin towards Staphylococcus aureus as bacterial model system for the study.

\section{MATERIALS AND METHODS}

\subsection{Compounds collection}

The following compounds were purchased from Extrasynthese (GenayCedex, France): caffeic acid, chlorogenic acid, ferulic acid, morin, quercetin, isoquercitrin, rutin and hesperidin. The selected antibiotic amoxicillin with clavulanic acid was purchased from Hemofarm (Vršac, Serbia). The phenolic compounds were dissolved in $30 \%$ ethanol, and antibiotic was dissolved in sterile water in concentration $1 \mathrm{mg} / \mathrm{mL}$.

\subsection{Microorganisms}

Two S. aureus strains (clinical isolate and ATCC 11632) were used. Clinical isolate was obtained from palatine tonsil of a patient after obtaining informed written consent, at Otorhinolaryngology clinic at Clinical Hospital Center Zvezdara, Belgrade, Serbia.The species were maintained in Triptone Soy Agar (TSA, Torlak, Serbia). The microorganisms are deposited at the Mycological Laboratory, Department of Plant Physiology, Institute for Biological Research "Siniša Stanković", Belgrade, Serbia.

\subsection{Antibacterial susceptibility test}

Microdilution method with some modifications (Kostić et al., 2017) was used to examine antibacterial activity of selected phenolic compounds. MICs were observed as the lowest concentrations with no visible bacterial growth. MBCs were determined by serial sub-cultivation of $10 \mu \mathrm{L}$ into microtiter plates containing $100 \mu \mathrm{L}$ of broth per well and further incubation at $37^{\circ} \mathrm{C}$ for $24 \mathrm{~h}$. The lowest concentration with no visible growth was defined as MBC. All experiments were repeated two times.

\subsection{Inhibition of biofilm formation}

The ability of phenolic compounds to inhibit biofilm formation was determined as described previously with some modifications (Kostić et al., 2020b). S. aureus cells were incubated in 96 well microtiter plates with adhesive bottom (Sarstedt, Germany) with MIC and sub-MIC concentrations of tested phenolic compounds at $37^{\circ} \mathrm{C}$ for 24 hours. Then, wells were washed twice with sterile PBS (Phosphate buffered saline, $\mathrm{pH}$ 7.4), and biofilms were fixed with methanol for $10 \mathrm{~min}$; next, methanol was removed and the plate was air dried and stained with $0.1 \%$ crystal violet (Bio-Merieux, France) for 30 min. Wells were washed with water, air dried and $100 \mu \mathrm{L}$ of $96 \%$ ethanol (Zorka, Serbia) was added to dissolve bounded crystal violet. The absorbance was read at $570 \mathrm{~nm}$ using a plate reader. The percentage of inhibition of biofilm formation was calculated by the formula:

$$
\text { Inhibition }(\%)=\frac{A_{\text {control }}-A_{\text {sample }}}{A_{\text {control }}} \times 100
$$

\subsection{Inhibition of formed biofilm}

Potential of selected phenolic compounds to disturb established biofilms was determined according to Smiljković et al. (2018). Strains of S. aureus were grown in Triptic soy broth enriched with $2 \%$ glucose in microtiter plates with adhesive bottom for $24 \mathrm{~h}$ at $37^{\circ} \mathrm{C}$. Wells were washed twice and the remaining biofilm was treated with tested compounds for $60 \mathrm{~s}$ at MBC values. The wells were washed; the remaining biofilm was fixed with methanol and after air drying, it was stained with $0.1 \%$ crystal violet. After dissolving the stain in ethanol, the absorbance was read and the percentage of destruction of already formed biofilm was calculated as mentioned above.

Table 1. Minimal inhibitory (MIC) and minimal bactericidal concentrations $(\mathrm{MBC})$ of phenolic compounds $(\mathrm{mg} / \mathrm{mL})$ against two Staphylococcus aureus isolates.

\begin{tabular}{lrrrrrr}
\hline \multirow{2}{*}{ Compound } & \multicolumn{2}{c}{ Clinical isolate } & & \multicolumn{2}{c}{ ATCC 11632} \\
\cline { 2 - 3 } \cline { 6 - 7 } \cline { 5 - 6 } & MIC & MBC & & MIC & MBC \\
caffeic acid & 0.4 & 0.4 & & 0.1 & 0.2 \\
chlorogenic acid & 0.4 & 0.4 & & 0.2 & 0.4 \\
ferulic acid & 0.4 & 0.4 & & 0.2 & 0.4 \\
morin & 0.2 & 0.4 & & 0.05 & 0.2 \\
quercetin & 0.2 & 0.4 & & 0.2 & 0.4 \\
isoquercitrin & 0.2 & 0.4 & & 0.1 & 0.2 \\
rutin & 0.4 & 0.8 & & 0.2 & 0.4 \\
hesperidin & 0.4 & 0.4 & & 0.2 & 0.4 \\
amox./clav. acid & 0.001 & 0.002 & & 0.001 & 0.002
\end{tabular}

a Amoxicillin with clavulanic acid are commercial antibiotics used as positive control

\section{RESULTS AND DISCUSSION}

Antibacterial activities of eight tested phenolic compounds against two strains of the $S$. aureus, are presented in Table 1 . The antibacterial activity was in the range of $0.05-0.4 \mathrm{mg} / \mathrm{mL}$ for inhibitory activity (MIC values), and $0.1-0.8 \mathrm{mg} / \mathrm{mL}$ for bactericidal activity (MBC). S. aureus ATCC 11632 was more susceptible to the application of examined phenolic compounds compared to $S$. aureus clinical isolate, MIC in range $0.05-0.2 \mathrm{mg} / \mathrm{mL}$ and $0.1-0.4 \mathrm{mg} / \mathrm{mL}$, respectively. Morin, caffeic acid and isoquercitrin showed the best activity against $S$. aureus ATCC 11632 (MIC values $0.05-0.1 \mathrm{mg} / \mathrm{mL}$ ). Against $S$. aureus clinical isolate morin, quercetin and isoquercitrin were the compounds with the best activity (MIC value $0.2 \mathrm{mg} / \mathrm{mL}$ ). Commercially available antibiotic amoxicillin with clavulanic acid proved to be more effective against $S$. aureus isolates than the phenolic compounds, but considering its side effects and raising antimicrobial resistance among pathogens the activity of naturally bioactive compounds is of great importance. In the past few years, there are several reports regarding antibacterial activity of caffeic acid (dos Santos et al., 2018; Lima et al., 2016; Kępa et al., 2018), chlorogenic acid (Adamczak et al., 2019; Li et al., 2014; Wang et al., 2015), ferulic acid (Borges et al., 2013; 2012), morin (Gutiérrez-Venegas et al., 2019), quecetrin (Adamczak et al., 2019; da Costa Júnior et al., 2018; Gutiérrez-Venegas et al., 2019), hesperidin (Lopes et al., 2017), and rutin (Gutiérrez-Venegas et al., 2019) against S. aureus different strains (Table 2).

Biofilm results indicated that among eight tested phenolic compounds, ferulic acid, morin, quercetin, and hesperidin inhibit 
Table 2. Previously reported minimal inhibitory concentrations (MIC) of selected phenolic compounds against different Staphylococcus aureus isolates

\begin{tabular}{|c|c|c|c|}
\hline \multirow[t]{2}{*}{ Compound } & \multirow[t]{2}{*}{ Isolate } & $\mathrm{MIC}$ & \multirow[t]{2}{*}{ Reference } \\
\hline & & {$[\mathrm{mg} / \mathrm{mL}]$} & \\
\hline \multirow[t]{3}{*}{ caffeic acid } & Clinical isolate & $\geq 1.024$ & Li et al. (2014) \\
\hline & ATCC 25923, ATCC 43300, ATCC 6538 & 0.256 & Kępa et al. (2018) \\
\hline & RN4220, 1199B & $>1.024$ & dos Santos et al. (2018) \\
\hline \multirow[t]{3}{*}{ chlorogenic acid } & ATCC 29213 & 2.56 & Li et al. (2014) \\
\hline & ATCC 25904, ATCC 25923, ATCC 29213 & $>1.024$ & Wang et al. (2015) \\
\hline & unknown & 1.000 & Adamczak et al. (2019) \\
\hline ferulic acid & CECT 976 & 1.100 & Borges et al. $(2013 ; 2012)$ \\
\hline morin & ATCC 25923 & 1.000 & Gutiérrez-Venegas et al. (2019) \\
\hline \multirow[t]{3}{*}{ quercetin } & Clinical isolates, ATCC 29213, ATCC 33591 & $0.001->0.256$ & da Costa Júnior et al. (2018) \\
\hline & ATCC 25923 & 0.050 & Gutiérrez-Venegas et al. (2019) \\
\hline & unknown & $>1.000$ & Adamczak et al. (2019) \\
\hline hesperidin & RN4220, SA1199B & $>1.024$ & Lopes et al. (2017) \\
\hline rutin & ATCC 25923 & 1.000 & Gutiérrez-Venegas et al. (2019) \\
\hline
\end{tabular}

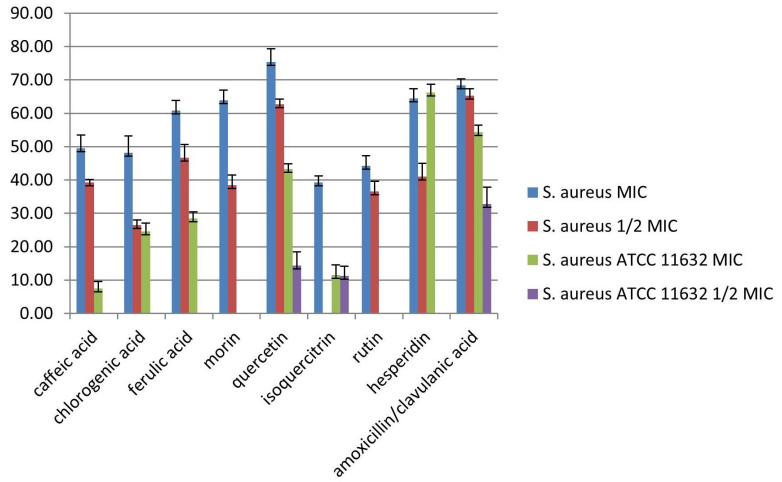

Fig. 1. Inhibition of $S$. aureus (clinical isolate) and S. aureus ATCC 11632 biofilm formation by phenolic compounds (\%).

S. aureus (clinical isolate) cell attachment for above the $60 \%$ at MIC value, while for $S$. aureus ATCC 11623 , only hesperidin showed inhibition of biofilm formation above $60 \%$ (Figure 1 ). Among the tested compounds, caffeic acid showed the lowest antibiofilm activity with an inhibition value of $7.5 \%$ (for $S$. aureus ATCC 11632) and isoquercitrin with $39 \%$ (for S. aureus clinical isolate). Isoquercitrin didn't exhibit antibiofilm activity towards S. aureus clinical isolate at sub-MIC value. Morin and rutin are two compounds which didn't show antibiofilm activity towards S. aureus ATCC 11632. Caffeic, chlorogenic, ferulic acids and morin, rutin and hesperidin didn't exhibit antibiofilm effect on S. aureus ATCC strain at sub-MIC (Figure 1). The effect of the $60 \mathrm{~s}$ treatment with different phenolic compounds on S. aureus established biofilms was tested. All examined compounds exhibited demolishing activity against established biofilms (Figure 2). The best activity was accomplished by hesperidin its application has reduced established biofilm biomass of $S$. aureus clinical isolate for $74 \%$, while quercetin demolished S. aureus ATCC 11632 biofilm for 57

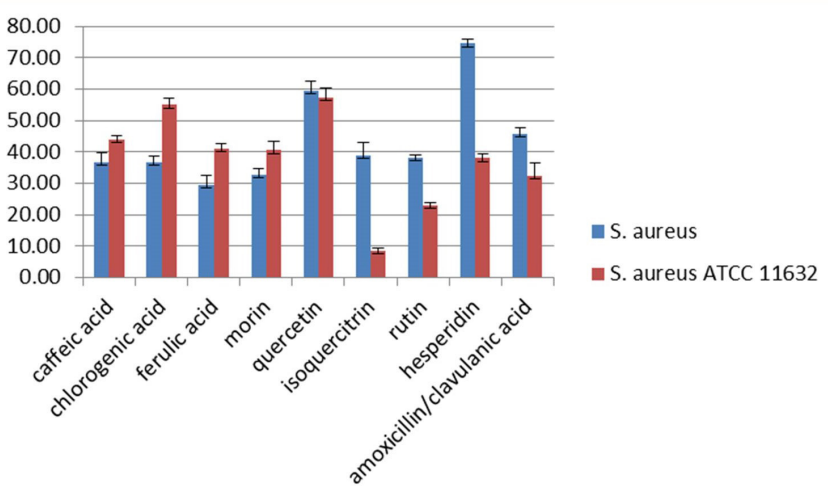

Fig. 2. Destruction of $24 \mathrm{~h}$ old S. aureus (clinical isolate and ATCC 11632) biofilms after $60 \mathrm{~s}$ treatment with MBC of phenolic compounds (\%).

$\%$. Isoquercitrin showed the lowest activity among the tested natural products. According to Cho et al. (2015), quercetin at $0.05 \mathrm{mg} / \mathrm{mL}$ significantly inhibits biofilm production of $S$. aureus ATCC 6538 strain after $24 \mathrm{~h}$ while in our study concentration of $0.2 \mathrm{mg} / \mathrm{mL}$ quercetrin was necessary for biofilm reduction. Abreu et al. (2016) demonstrated effect of the morin and quercetin in biofilm prevention, when they were applied alone or in combination with antibiotics. Morin $(500 \mathrm{mg} / \mathrm{L})$ applied for $1 \mathrm{~h}$ caused high CFU reduction (1.2-2.1 CFU $\left.\mathrm{cm}^{2}\right)$ than quercetrin and antibiotics, but after $24 \mathrm{~h}$, both morin and quercetrin showed activity in preventing biofilm formation of SA1199B and XU212 strains. In the combination, tetracycline combined with pyrrolidine and morin showed promising effect against XU212 strain.

Phenolic acids have shown the similar behaviour in microdilution test against free floating cells and against microbial biofilm. It could be presumed that glycosylation of flavonoids (quercetin as aglycon) contributes to the lower ac- 
tivity recorded in the tests of antibiofilm activity. However glycosylation of flavonoids seemed to have better or no effect on MICs than aglycone forms, depending on substitution position of sugars, as shown by the results of microdilution method. According to Méndez and Salas (2001) and Hyung Ko et al. (2006), sugar ligands can mediate drug targeting and biological activity. Overall, glycosylated molecules were less active against microbial biofilms, and their activity seemed to be time dependant. Overall, all of the phenolic compounds expressed the activities investigated in the current study. It seems that antimicrobial potential of phenolic acids versus flavonoids was subordinated to chemical structures of individual compounds.

\section{CONCLUSION}

The results obtained in this work indicate that phenolic compounds, particulary morin possess promising antibacterial activity. Furthermore, all tested compounds exhibited promising antibiofilm potential in both assays - feature especially accomplished by quercetin and morin. The observed antimicrobial and antibiofilm potential of phenolic compounds can serve as one step more towards the development of novel treatment for the $S$. aureus infections.

\section{ACKNOWLEDGMENTS}

This work has been supported by the Serbian Ministry of Education, Science and Technological Development with financial support (Grant number451-03-68/2020-14/200007).

\section{REFERENCES}

Abreu, A. C., Saavedra, M. J., Simões, L. C. and Simões, M. (2016). Combinatorial approaches with selected phytochemicals to increase antibiotic efficacy against Staphylococcus aureus biofilms, Biofouling 32(9): 1103-1114.

Adamczak, A., Ożarowski, M. and Karpiński, T. M. (2019). Antibacterial activity of some flavonoids and organic acids widely distributed in plants, Journal of Clinical Medicine 9(1): 109 .

Borges, A., Ferreira, C., Saavedra, M. J. and Simões, M. (2013). Antibacterial activity and mode of action of ferulic and gallic acids against pathogenic bacteria, Microbial Drug Resistance 19(4): 256-265.

Borges, A., Saavedra, M. J. and Simões, M. (2012). The activity of ferulic and gallic acids in biofilm prevention and control of pathogenic bacteria, Biofouling 28(7): 755-767.

Chalmers, S. J. and Wylam, M. E. (2020). Methicillin-resistant Staphylococcus aureus infection and treatment options, in Y. Ji (ed.), Methicillin-resistant Staphylococcus aureus (MRSA) protocols, Vol. 2069, Springer US, New York, NY, pp. 229-251. Series Title: Methods in Molecular Biology.

Cho, H. S., Lee, J.-H., Cho, M. H. and Lee, J. (2015). Red wines and flavonoids diminish Staphylococcus aureus virulence with anti-biofilm and anti-hemolytic activities, Biofouling 31(1): 1-11.

Ćirić, A., Petrović, J., Ivanov, M., Kostić, M. and Soković, M. (2020). Recent advances in science of quorum sensing, in V. R. Rai and J. A. Bai (eds), Trends in quorum sensing and quorum quenching, 1 edn, CRC Press, pp. 225-241.

Craft, K. M., Nguyen, J. M., Berg, L. J. and Townsend, S. D. (2019). Methicillin-resistant Staphylococcus aureus (MRSA): antibiotic-resistance and the biofilm phenotype, MedChemComm 10(8): 1231-1241. da Costa Júnior, S., de Oliveira Santos, J., de Almeida Campos, L., Pereira, M., Santos Magalhães, N. and Ferro Cavalcanti, I. (2018). Antibacterial and antibiofilm activities of quercetin against clinical isolates of Staphyloccocus aureus and Staphylococcus saprophyticus with resistance profile, International Journal of Environment, Agriculture and Biotechnology 3(5): 1948-1958.

dos Santos, J. F., Tintino, S. R., de Freitas, T. S., Campina, F. F., de A. Menezes, I. R., Siqueira-Júnior, J. P., Coutinho, H. D. and Cunha, F. A. (2018). In vitro in silico evaluation of the inhibition of Staphylococcus aureus efflux pumps by caffeic and gallic acid, Comparative Immunology, Microbiology and Infectious Diseases 57: 22-28.

Figueiredo, A. M. S., Ferreira, F. A., Beltrame, C. O. and Côrtes, M. F. (2017). The role of biofilms in persistent infections and factors involved in ica-independent biofilm development and gene regulation in Staphylococcus aureus, Critical Reviews in Microbiology 43(5): 602-620.

Gutiérrez-Venegas, G., Gómez-Mora, J. A., Meraz-Rodríguez, M. A., Flores-Sánchez, M. A. and Ortiz-Miranda, L. F. (2019). Effect of flavonoids on antimicrobial activity of microorganisms present in dental plaque, Heliyon 5(12): e03013.

Hyung Ko, J., Gyu Kim, B. and Joong-Hoon, A. (2006). Glycosylation of flavonoids with a glycosyltransferase from Bacillus cereus, FEMS Microbiology Letters 258(2): 263-268.

Ivanov, M., Kannan, A., Stojković, D., Glamočlija, J., Grdadolnik, S. G., Sanglard, D. and Soković, M. (2020). Revealing the astragalin mode of anticandidal action, EXCLI Journal 19: $1436-1445$.

Kerekes, E. B., Vidács, A., Takó, M., Petkovits, T., Vágvölgyi, C., Horváth, G., Balázs, V. L. and Krisch, J. (2019). Anti-biofilm effect of selected essential oils and main components on mono- and polymicrobic bacterial cultures, Microorganisms 7(9).

Kostić, M., Ivanov, M., Babić Sanković, S., Petrović, J., Soković, M. and Ćirić, A. (2020a). An up-to-date review on bioresource therapeutics effective against bacterial species frequently associated with chronic sinusitis and tonsillitis, Current Medicinal Chemistry 27(41): 6892-6909.

Kostić, M., Ivanov, M., Fernandes, Â., Pinela, J., Calhelha, R., Glamočlija, J., Barros, L., Ferreira, I., Soković, M. and Ćirić, A. (2020b). Antioxidant extracts of three Russula genus species express diverse biological activity, Molecules 25(18): 4336

Kostić, M., Smiljković, M., Petrović, J., Glamočlija, J., Barros, L., Ferreira, I., Ćirić, A. and Soković, M. (2017). Chemical, nutritive composition and a wide range of bioactive properties of honey mushroom Armillaria mellea (Vahl: Fr.) Kummer, Food \& Function 8(9): 3239-3249.

Kourtis, A. P., Hatfield, K., Baggs, J., Mu, Y., See, I., Epson, E., Nadle, J., Kainer, M. A., Dumyati, G., Petit, S., Ray, S. M., Emerging Infections Program MRSA author group, Ham, D., Capers, C., Ewing, H., Coffin, N., McDonald, L. C., Jernigan, J. and Cardo, D. (2019). Vital signs: Epidemiology and recent trends in methicillin-resistant and in methicillinsusceptible Staphylococcus aureus bloodstream infections United States, MMWR. Morbidity and Mortality Weekly Report 68(9): 214-219.

Kępa, M., Miklasińska-Majdanik, M., Wojtyczka, R. D., Idzik, D., Korzeniowski, K., Smoleń-Dzirba, J. and Wassik, T. J. 
(2018). Antimicrobial potential of caffeic acid against Staphylococcus aureus clinical strains, BioMed Research International ISSN: 2314-6133 Pages: e7413504 Publisher: Hindawi Volume: 2018

Li, G., Qiao, M., Guo, Y., Wang, X., Xu, Y. and Xia, X. (2014). Effect of subinhibitory concentrations of chlorogenic acid on reducing the virulence factor production by Staphylococcus aureus, Foodborne Pathogens and Disease 11(9): 677-683.

Lima, V. N., Oliveira-Tintino, C. D., Santos, E. S., Morais, L. P., Tintino, S. R., Freitas, T. S., Geraldo, Y. S., Pereira, R. L., Cruz R. P., Menezes, I. R. and Coutinho, H. D. (2016). Antimicrobial and enhancement of the antibiotic activity by phenolic compounds: Gallic acid, caffeic acid and pyrogallol, Microbial Pathogenesis 99: 56-61.

Lopes, L. A. A., dos Santos Rodrigues, J. B., Magnani, M., de Souza, E. L. and de Siqueira-Júnior, J. P. (2017). Inhibitory effects of flavonoids on biofilm formation by Staphylococcus aureus that overexpresses efflux protein genes, Microbial Pathogenesis 107: 193-197.

Manandhar, S., Singh, A., Varma, A., Pandey, S. and Shrivastava, N. (2018). Biofilm producing clinical Staphylococcus aureus isolates augmented prevalence of antibiotic resistant cases in tertiary care hospitals of Nepal, Frontiers in Microbiology 9: 2749.

Méndez, C. and Salas, J. A. (2001). Altering the glycosylation pattern of bioactive compounds, Trends in Biotechnology 19(11): 449-456.

Moormeier, D. E. and Bayles, K. W. (2017). Staphylococcus aureus biofilm: a complex developmental organism: molecular mechanisms of $S$. aureus biofilm development, Molecular Microbiology 104(3): 365-376.

Slobodníková, L., Fialová, S., Rendeková, K., Kováč, J. and Mučaji, P. (2016). Antibiofilm activity of plant polyphenols, Molecules 21(12): 1717.

Smiljković, M., Dias, M. I., Stojković, D., Barros, L., Bukvički, D., Ferreira, I. C. F. R. and Soković, M. (2018). Characterization of phenolic compounds in tincture of edible Nepeta nuda: development of antimicrobial mouthwash, Food $\mathcal{E}$ Function 9(10): 5417-5425.

Smiljković, M., Kostić, M., Stojković, D., Glamočlija, J. and Soković, M. (2019). Could flavonoids compete with synthetic azoles in diminishing Candida albicans infections? A comparative review based on in vitro studies, Current Medicinal Chemistry 26(14): 2536-2554.

Smiljkovic, M., Stanisavljevic, D., Stojkovic, D., Petrovic, I., Marjanovic Vicentic, J., Popovic, J., Golic Grdadolnik, S., Markovic, D., Sankovic-Babice, S., Glamoclija, J., Stevanovic, M. and Sokovic, M. (2017). Apigenin-7-O-glucoside versus apigenin: Insight into the modes of anticandidal and cytotoxic actions, EXCLI Journal 16: 795-807.

Stojković, D., Jevremović, K., Smiljković, M., Živković, J. and Soković, M. (2018). Inhibition of microbial biofilm formation by Cydonia oblonga Mill. fruit peel and leaf ethanolic extracts, Lekovite sirovine 38: 58-61.

Stojković, D., Petrović, J., Soković, M., Glamočlija, J., KukićMarković, J. and Petrović, S. (2013). In situ antioxidant and antimicrobial activities of naturally occurring caffeic acid, $p$-coumaric acid and rutin, using food systems: In situ antioxidant and antimicrobial activities of naturally occurring caffeic acid, Journal of the Science of Food and Agriculture 93(13): 3205-3208.
Wang, L., Bi, C., Cai, H., Liu, B., Zhong, X., Deng, X., Wang, T., Xiang, H., Niu, X. and Wang, D. (2015). The therapeutic effect of chlorogenic acid against Staphylococcus aureus infection through sortase A inhibition, Frontiers in Microbiology 6: 1031 .

Warraich, A. A., Mohammed, A. R., Perrie, Y., Hussain, M., Gibson, H. and Rahman, A. (2020). Evaluation of antibiofilm activity of acidic amino acids and synergy with ciprofloxacin on Staphylococcus aureus biofilms, Scientific Reports 10(1): 9021. 